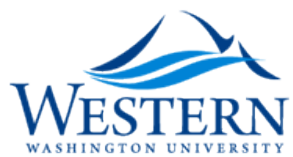

Western Washington University

Western CEDAR

1986

\title{
Polynesian Women and Tifaifai Fabrications of Identity
}

Joyce D. Hammond

Western Washington University, joyce.hammond@wwu.edu

Follow this and additional works at: https://cedar.wwu.edu/anthropology_facpubs

Part of the Social and Cultural Anthropology Commons

\section{Recommended Citation}

Hammond, Joyce D., "Polynesian Women and Tïfaifai Fabrications of Identity" (1986). Anthropology Faculty and Staff Publications. 11. https://cedar.wwu.edu/anthropology_facpubs/11

This Article is brought to you for free and open access by the Anthropology at Western CEDAR. It has been accepted for inclusion in Anthropology Faculty and Staff Publications by an authorized administrator of Western CEDAR. For more information, please contact westerncedar@wwu.edu. 
Polynesian Women and Tīfaifai Fabrications of Identity

Author(s): Joyce D. Hammond

Source: The Journal of American Folklore, Vol. 99, No. 393 (Jul. - Sep., 1986), pp. 259-279

Published by: American Folklore Society

Stable URL: http://www.jstor.org/stable/540805

Accessed: 02-06-2015 17:36 UTC

Your use of the JSTOR archive indicates your acceptance of the Terms \& Conditions of Use, available at http://www.jstor.org/page/ info/about/policies/terms.jsp

JSTOR is a not-for-profit service that helps scholars, researchers, and students discover, use, and build upon a wide range of content in a trusted digital archive. We use information technology and tools to increase productivity and facilitate new forms of scholarship. For more information about JSTOR, please contact support@jstor.org. 


\section{Polynesian Women and Tĩfaifai Fabrications of Identity}

Women of Polynesia utilize the reintegrated art form of tifaifai to express their complex and multifaceted identities. Through their work patterns, aesthetic decisions, and designated uses for tiffaifai, women create and reflect diverse and overlapping roles such as those associated with kinship relations, regional identities, religious affiliations, and gender expectations.

THE RECOGNITION OF THE DYNAMIC, processual aspect of art as a communication system has led to a variety of approaches in studying the visual arts of non-Western people. Research has revealed the communicative processes of artistic activity in terms of social structure, social relations, cultural values, and cultural change. A major theme that emerges throughout much of the research on the folk arts of non-Western peoples, while often not explicitly stated, is the idea of a single cultural identity and, concomitantly, an artist archetype (Smith 1961; D’Azevedo 1966; Forge 1967). Discussions of individual artists' expressions are relatively rare (Gerbrands 1967; Wahlman 1974; Willett 1978), partly as a result of the researcher's focus on the group and broad, theoretical perspectives, but also as a consequence of a long historical trend to treat folk arts as products of anonymous creators. Research into the expression of individual identity in women's folk arts of non-Western societies is further reduced by the fewer studies devoted to women's activities in general (Teilhet 1978), a hiatus that is now well recognized as problematic in the androcentric biases of the various academic disciplines. Here, I seek to add to a small, but growing, corpus of literature on women's folk arts in non-Western cultures, and specifically to address the question of the means by which individuals may express themselves and actively create aspects of their identities through a visual art form.

The study of tiffaifai, ${ }^{1}$ piecework and appliqué textiles, provides a unique opportunity to explore the means by which women of the Hawaiian, Society, Cook, and Austral Islands of eastern Polynesia have utilized the process and product of an art form for personal expression over the past 175 years. The diachronic as well as synchronic focus of this paper offers a perspective on 
the ways in which Polynesian women have expressed many different facets of their identities.

While there is some recent work which examines women's use of traditional folk art forms as a personal means of expression (see, for example, Dewhurst et al. 1979; Whitten and Whitten 1976; Munn 1973; Cooper and Buferd 1977), far fewer studies have been conducted on women's reliance upon reintegrated arts for the same purpose (Salvador 1978; Brotten and Lang 1973; Eber 1972). Yet, in light of the syncretic nature of reintegrated art forms and their evolution as a result of culture contact, reintegrated arts are particularly well suited to an examination of the ways in which women may utilize an art form to recreate their identities. This paper provides insights into the complex interaction between art and artist by looking at the ways in which Polynesian women express themselves and shape their own identities by creating and using tîfaifai.

\section{Selection and Self-Expression}

As a reintegrated art form (a term proposed by Graburn [1976:6] to refer to art forms which are "new syntheses . . . developed by taking some ideas, materials or techniques from the industrial society [with which the Fourth World Society has come into contact] and applying them in new ways to the needs of the small-scale peoples") tiffaifai evolved from the combined influences of Western quilts and precontact bark cloth traditions. Similar to other syncretic arts, tiffaifai reflect the interaction and modification of elements from two cultures. O'Reilly (1959) and Kaeppler (1979), writing on two regional forms, have both remarked upon the reintegrative character of tiffaifai, emphasizing the Polynesian expression or "sentiment" which permeates the adopted materials, structure, and techniques.

The distinctively Polynesian character to which O'Reilly and Kaeppler refer originated in the indigenous bark cloth traditions of Polynesia. With some local variation, the techniques of bark cloth manufacture were essentially the same throughout Polynesia. The islanders carefully cultivated and harvested the trees, after which the women peeled off the bark of the trees' stems in one piece and separated the inner and outer bark. After soaking the inner bark in fresh water or sea water, the women beat it with hand-held wooden beaters on a wooden anvil. This process broke down the inner bark fibers, stretched the bark, and made it more flexible. Depending on such variables as the type of bark used, the amount of time the inner bark was soaked before beating, and the number and size of grooves carved on the bark cloth beater, a woman could create bark cloth that varied in texture from a very thick, coarse material to a soft and delicately thin material.

Sometimes bark cloth was left in its natural state, but often the material was dyed by immersion and/or decorated with techniques such as handpainting, stenciling, and printing. The range of colors, derived from regional dyes and pigments, varied from one locality to another, but yellows, reds, browns, and 
blacks were the most common colors used throughout Polynesia. Most bark cloth designs were geometric, but some naturalistic designs, such as the famous leaf imprint designs of Tahitian bark cloth, were also employed.

Bark cloth was a form of wealth in Polynesia; its importance derived from the many roles it played in the social and economic lives of the people. The presentation of bark cloth was often used to symbolize the validation of a political or social agreement. Polynesians also ceremoniously bestowed bark cloth upon people during birth, puberty, marriage, and death rituals. The presentation and exchange of bark cloth during rites of passage served to honor a person and to validate and solidify the social and economic bonds among people participating in such rites.

One of the primary uses of bark cloth was as clothing. Depending on the quality and amount of decoration, bark cloth served from everyday apparel to costumes for special ceremonies and purposes. Often, fine or decorated bark cloth indicated a person's social status. There were also bark cloth bedcovers and room partitions. As room dividers, sheets of bark cloth sometimes served as mosquito nets, but they also lent privacy and beauty to the islanders' homes.

As Sanday (1974), Boserup (1970), and others have demonstrated, Polynesian women's participation in the economic production and distribution of valued goods contributed to their high status in their societies. In addition to their contributions to subsistence activities, the production of fine mats and bark cloth gave women a significant role in the prestige economies of their societies, particularly since, in many cases, women had some control over the distribution of the valued goods they created.

Throughout the islands, primarily women were involved in the manufacture of bark cloth. They took great pride in their skills since social prestige accrued to women of all classes who worked well with bark cloth. Missionary William Ellis's remarks about Tahitian women are instructive:

In the manufacture of cloth, the females of all ranks were employed; and the queen, and wives of the chiefs of the highest rank, strove to excel in some department-in the elegance of the pattern, or the brilliancy of the colour. They are fond of society, and worked in large parties, in open and temporary houses erected for the purpose. Visiting one of these houses at Eimeo, I saw sixteen or twenty females all employed. The queen sat in the midst, surrounded by several chief women, each with a mallet in her hand, beating the bark that was spread before her. The queen worked as diligently and cheerfully as any present.

As the wives and daughters of the chiefs take a pride in manufacturing superior cloth, the queen would often have felt it derogatory to her rank, if any other females in the island could have finished a piece of cloth better than herself. [Ellis 1969[1831]:184-185]

The importance of bark cloth and, concomitantly, the prestige women gained from creating it disappeared in many Polynesian societies with the influx of Westerners into the Pacific in the 19th century. Western cloth replaced bark cloth on many islands at a fairly early date. In Tahiti, for example, bark cloth was not produced after about 1830. 
To some extent, the decline of bark cloth manufacture was due to a variety of environmental factors precipitated by Western influence (e.g., the neglect of plant cultivation), but in many cases, Polynesians discontinued making it because Western cloth proved more practical. Imported fabric was easier and less time-consuming to fashion into clothes and household goods, and it had the advantage of being durable and washable, which bark cloth did not. Yet, Western cloth did share one very important quality with the bark cloth it replaced. It was valued as a prestige item, largely because it was a foreign good introduced by a powerful people. Islanders were eager to obtain Western fabric as Smith's account of the Tahitian sovereign, Pomarre II, reveals. The king wrote, "Friends, send also property and cloth for us, and we also will adopt English customs" (Smith 1825:62).

Although Polynesian women could no longer sustain the esteem associated with their roles as producers of bark cloth, they quickly adapted to the changing circumstances of the day. For, when missionaries introduced the Western quilt, made from brightly colored pieces of the highly coveted Western fabric and involving substantial investments of skill and time, comparable to the production of bark cloth, Polynesians perceived the quilts as a worthy replacement for bark cloth used in ritual contexts. Thus, with the adoption of Western quilts, Polynesian women pursued a new means by which to maintain their identities as creators of socially valuable textiles. ${ }^{2}$

The first record of the introduction of quilting into Polynesia is from the Hawaiian Islands where New England protestant missionaries taught high ranking Hawaiian women how to quilt. On 3 April 1820, seven young New England missionary women of the American Board of Missions held a sewing circle aboard the Thaddeus, which had recently arrived from America. Lucy Thurston, one of the missionaries, recorded that four Hawaiian women of rank attended: Kalakua, mother of the young king Liholiho; Namahana, her sister and a widow of the first Hawaiian king, Kamehameha I; and two wives of Chief Kalanimoku.

Kalakua, queen dowager, was directress. She requested all the seven white ladies to take seats with them on mats, on the deck of the Thaddeus. Mrs. Holman and Mrs. Ruggles were executive officers, to ply the scissors and prepare the work. . . . The four women of rank were furnished with calico patchwork to sew,-a new employment to them. [Thurston 1882:32]

The act of sewing calico piecework was a new employment to the aristocratic Hawaiian women, but the work patterns associated with quilting were not. Women often worked in groups when making bark cloth, and sometimes a leader directed the process.

Thus, when missionaries presented the quilt as a domestic art form of Christian households, requiring the efforts of a group of women, Hawaiian women easily adapted traditional work patterns to new skills. Missionaries probably first taught quilting to women of the royal households as a strategy to influence the general populace. However, Hawaiian women of rank, who had al- 
ways created fine bark cloth and gained prestige from the work, may have thought it quite logical that they should learn quilting first.

Specific documentation for the earliest introduction of the Western quilting tradition into other areas of eastern Polynesia is unavailable. In some cases, missionaries may have been the first to introduce quilting designs and techniques, but in some areas Polynesians themselves must have introduced the Western quilting tradition as a result of contacts with other Polynesians or Western missionaries on neighboring islands.

Once in the hands of the Polynesian women, the Western quilting tradition became the reintegrated art form of tifaifai as a result of the selective process women exercised in adopting certain designs and construction techniques to serve their purposes. This selection process constituted a conscious means for Polynesian women to express their aesthetic preferences from their own cultural background. Thus, while Western piecework quilts provided models for the earliest forms of Polynesian tîfaifai, many of the design principles and construction techniques "borrowed" from the Western quilting tradition and accepted by Polynesian women were direct extensions of bark cloth traditions applied to a new medium. For example, Polynesian women had often used relatively small geometric designs, similar to Western piecework designs, regularly and symmetrically stamped or painted onto bark cloth. Likewise, they created different areas of color beside one another in bark cloth, just as Western women did in creating piecework quilts.

Bark cloth and cotton material, though different, were similar enough as fabric to also allow women to use similar design principles in the construction of bark cloth and tiffaifai. In fact, the material correspondence which Hawaiians saw between their indigenous bark cloth and the introduced Western quilts was so strong that it was reflected in the term kapa which they applied to both. The striking similarity between Western quilts and Hawaiian sleeping blankets probably prompted Hawaiian women to retain the three-layered construction of the Western quilt in their creations. Because the multilayered construction of the Hawaiian quilt is unique among tiffaifai traditions, there is strong evidence to indicate that the Hawaiian women imitated the multilayered construction of Western quilts and the technique of quilting in response to the same climatic conditions which formerly prompted them to make the bark cloth sleeping blankets, composed of several layers of bark cloth attached together at one end. Hawaiian women may also have retained the actual quilting techniques of the Western quilt (another characteristic unique among the tifaifai traditions) owing to the similarity between Western quilting designs and the watermark designs of 19th-century Hawaiian bark cloth created by pressing the carved side of a bark cloth beater against damp cloth during the final stages of beating. ${ }^{3}$

Throughout eastern Polynesia, women may have been quick to accept particular Western piecework quilt designs which were similar to the geometric designs they had used in bark cloth because the designs looked familiar. Indeed, the piecework designs of many historical and contemporary tîfaifai 
throughout eastern Polynesia have counterparts in Western piecework quilts, but Polynesian women have often reinterpreted Western quilt designs in order to make them more meaningful to the islanders' experience. For example, a particular curved design known as "Drunkard's Path" in American quilt terminology is called $P \bar{a}^{\prime}$ aro in the Society Islands and the Austral Islands, the same name that islanders use for the curved knife and the act of using it to scoop coconut meat out of the shell.

Although early writers' remarks and historic photographs confirm that piecework was the most common style in the early phase of all tifaifai traditions ${ }^{4}$ the applique style quickly developed in many areas. In the same way that Polynesian women combined Western piecework quilt elements with bark cloth to create piecework tîfaifai, they borrowed elements of Western applique quilts and combined them with artistic principles used in bark cloth to fashion appliqué tîfaifai.

Based on early historical documents and the presence of missionaries in the Hawaiian Islands beginning in 1820 , it seems most likely that the Polynesian appliqué style, like the piecework, originated in the Hawaiian Islands. Appliqué quilts appeared early in the history of Hawaiian quilting, quickly grew in importance and soon gained a popularity there which overshadowed the piecework style.

To a degree, the Hawaiian appliqué quilt resulted from a Hawaiian modification of Western appliqué quilts. Such quilts did exist at the time the missionaries introduced the more practical piecework quilt of everyday use. Although the applique style quilts were probably in less abundance, the missionaries undoubtedly had some to spread on their beds for special occasions, just as they had done in New England. There are many indications that the aura of prestige and wealth associated with the less common Western applique quilt may have influenced the Hawaiians in their selection of a quilt style to emulate. $^{5}$

The historical development of the Hawaiian appliqué quilt also appears to be directly linked to characteristics of Hawaiian bark cloth sleeping blankets. In her work on Hawaiian quilts, Plews (1973:2) recalls:

my grandfather telling me that the kuina-kapa-papa'u [an indigenous Hawaiian sleeping cover made from bark cloth] consisted generally of four white sheets of tapa [sic] and a top gaily colored and patterned one, all sewn together at one end, was a very warm and cozy covering.

Plews believes that the Hawaiian applique quilt descended from the bright outer bark cloth layer (kilohana or ku'inakapa). This idea is also supported by Jones (1973:11), and is further substantiated by the most popular color combination in early Hawaiian appliqué quilts-brilliant red on white. This striking color combination may be directly attributed to the basic red on white color scheme used for some of the decorated top sheets in bark cloth sleeping covers.

The Hawaiian appliqué quilt almost certainly had direct and indirect influence on the origin and development of other appliqué tîfaifai traditions. The 
idea that extensive borrowing of tîfaifai designs and techniques took place among islanders is supported by informants' remarks on past occurrences and by contemporary trends in tiffaifai traditions. Yet, despite the inter-island borrowing of ideas, the distinctive regional tîfaifai traditions in appliqué (as well as piecework) styles, argue for the modification of artistic principles in line with regional aesthetics. In the Society Islands, for example, the applique style may well have been influenced by a former custom of Tahitian women to create distinctive bark cloth designs by imprinting leaves dipped in red dye onto the fabric. Although Society Islands appliqué designs of leaves and flowers are arranged much differently from the more random placement of bark cloth leaf impressions, the artistic principle expressed by applying an organic design onto a background is the same. Therefore, whether or not the Society Islands appliqué tîfaifai were directly influenced by the traditional bark cloth designs, the artistic choices arose from the same source.

Evolving from a common piecework style, the regional forms of piecework and appliqué tîfaifai became increasingly differentiated from one another. Today, the mosaic-like patterns of the iripiti of the Austral Islands, the beautifully executed embroidery of Cook Islands tivaevae, the undulating waves of quilting in Hawaiian quilts, and the simple elegance of color combinations in Society Islands tiffaifai are only some of the characteristics of the rich and varied spectrum of contemporary tifaifai traditions. ${ }^{6}$ The various regional styles reflect several generations of women's selection of artistic elements which had their origins in the regional styles of bark cloth and, as such, are statements of their creators' cultural identification.

Just as the aesthetic principles of tîfaifai traditions have been drawn from both Western and Polynesian sources, the uses of tifaifai reflect traditional roles of bark cloth as well as innovative uses arising from cultural change. In rites of passage ceremonies, tiffaifai have replaced the use of bark cloth as a highly esteemed gift presented to the individual undergoing transition. Sometimes they are also used as decoration for the area in which the rites are celebrated. In the past, bark cloth was used throughout eastern Polynesia as a socially valuable gift to confirm a change in social status and to establish bonds between participating parties; today, tîfaifai figure importantly as gifts for such life passage ceremonies as birthdays, coming of age ceremonies, and weddings.

Various cyclic ceremonies illustrate another way in which tîfaifai have replaced some of the functions of bark cloth. For example, in parts of eastern Polynesia, the contemporary celebration of the new year still retains practices dating to precontact Polynesian society. Throughout the Society and Austral Islands, tiffaifai are used to decorate the walls and the many beds of Polynesians' homes for the new year. In a spirit reminiscent of the way in which bark cloth was once spread out upon lines at the disposal of spiritual guests, tîfaifai are now used to decorate homes to honor neighbors and relatives who visit on New Year's Day.

The presentation of tîfaifai to high-status individuals in order to honor them is the third major way in which tîfaifai are used throughout eastern Polynesia. 
A traditional method of presentation is often used. The practice of wrapping a tîfaifai around a government or church official has direct historical antecedents in the practice of draping bark cloth around honored individuals' shoulders.

\section{Choices for Communication}

Women design, create, distribute, and designate uses for tiffaifai. With few exceptions, women make all decisions about tiffaifai. While many women do not create them, nearly every woman owns at least one tiffaifai and usually more. Throughout eastern Polynesia, therefore, tîfaifai belong to the domain of feminine achievement and expression.

There are three separate ways in which a Polynesian woman may use tîfaifai to express herself. She may communicate personal information through her decisions concerning work patterns related to the technical execution of the textiles, in decisions concerning the aesthetics of the art form itself, and in designated uses for the tîfaifai. Although the tîfaifai as object provides a point of reference for all three communication areas, based on the fact that women's work patterns, artistic choices, and decisions about tîfaifai uses revolve around the textiles, it is essential to recognize that the tiffaifai as object is only a part of the complex process by which women may create and express their identities.

Each of the three tiffaifai communication areas may serve as an independent sphere for a woman to express aspects of her sense of identity. This is particularly evident when a woman is involved in only one of these decision making areas, as, for example, when a woman purchases a tiffaifai from someone else and decides how it shall be used. Each area of self-expression, therefore, must be considered as a separate communication sphere. At the same time, it should be noted that whenever a woman communicates in a particular area, the information is often influenced by direct or indirect decisions in other areas. Thus, a woman who purchases a tîfaifai for a specific purpose may take the quality of execution into account as well as the tiffaifai design or other aesthetic features when she buys the tîfaifai.

Within each of the three tifaifai decision making areas, a woman is able to communicate a wide range of meanings. By engaging in the decision process in more than one area, a woman greatly expands the possibilities inherent in using tiffaifai as a means to create and express her identity. The depth and complexity of communication deepen with a woman's involvement in more than one area. Indeed, the ways in which messages of identity expressed in one area reinforce or elaborate upon expressions of identity in other areas lend particular significance to women's use of the art form and associated activities. Furthermore, by engaging in one or more areas of decision making over time and by engaging in different combinations of involvement in the three communication areas with several tiffaifai simultaneously, a woman can expand the possibilities for self-expression even further. Thus, a woman has many options for utilizing tîfaifai as a symbol of herself. The dynamic aspect of her 
decision making processes enables a woman to communicate a sense of the richness and complexity of her many roles.

In the past, many women of all ages made tîfaifai. Women sometimes learned from friends or by simply observing the art, but most of the learning process took place in the family. Mothers, grandmothers, and aunts taught young girls to make tîfaifai. As the following story indicates, the teaching process was, at times, selective.

When Josephine Leimalama Kamakau Hanakahi was growing up in Paia, Maui, her mother made Hawaiian quilts and gave one to each of her six brothers and sisters but none to Josephine. "Mama, what about me?" the child asked. Her mother replied, "My gift to you is teaching you the art of kapa ku'iki' [Hawaiian quilting].” [Altonn 1975]

Over the years, fewer women have pursued the skills requisite for creating tîfaifai. Although some schools teach Polynesian girls to make tîfaifai as a part of their curriculum, many young Polynesian women never learn to create them and express no desire to acquire the skills. In addition, many mature women either disavow any ability to create tîfaifai or express disinterest. Therefore, a woman's decision to make tîfaifai alone or within a group context is an individual expression which arises from her own desire and not from societal pressure to conform to a feminine role.

While the decision to work on a tiffaifai alone may reflect a woman's selfimage as a person who must accommodate herself to established roles (as, for example, in the case of some women who prefer to work independently because they feel they can't find time to work with others), in most cases, the decision to work alone appears to be an active means by which a woman can control decision making in artistic choices, tîfaifai uses, or both. She may work by herself to express her identity as an individual artist, an independent agent in social contexts, a self-employed business woman, or a combination of these roles. Many women express a preference to work independently because they wish to have complete control over all aspects of the creative process. They often say they prefer to work alone to ensure uniformity in their tiffaifai. The decision as to how the tifaifai shall be used often operates in conjunction with a woman's desire to control artistic choices, as, for instance, in her decision to make one for exhibit or sale. Increasingly, women who create tîfaifai for profit prefer to work alone for full monetary benefits.

In Tahiti, where many women sell tiffaifai to local clients, there is often a twostep individual creative process. The seller buys the fabric and then cuts and bastes the appliqué design onto the background material. The buyer herself sews the tîfaifai or commissions another woman to perform the task.

While there are women who consistently work alone, many women make some tīfaifai independently and other tîfaifai within a group. In terms of practical considerations, a woman who works within a group context can expect others to contribute their time, labor, special skills (and, in some instances, fabric) to the creation of a tiffaifai. The emphasis on sharing resources within 
the group context allows a woman to support members of the group and their common goals, to express her generosity, and to exhibit her skills.

Different groups of women vary in their approaches to making tîfaifai. On the island of Rarotonga in the Cook Islands, one women's group divides the work into equal portions for each member. Members share work in each $t \bar{i}$ faifai created, and each woman takes her turn in receiving a finished one. As a result of the work process, several women own the same design.

On Rurutu, located in the Austral Islands, a group of women from the same village trade skills with one another on a round-robin basis in order to produce different kinds of handicraft, such as purses, hats, and mats, to sell or use for their own purposes. Three or four women under the direction of a skilled creator also make tiffaifai upon request for other group members. A woman who wishes to trade her labor for a tiffaifai may do so by participating in the group's activities. Although she must purchase the fabric, she exchanges her handicraft skills for the labor of those women best qualified to make her tiffaifai.

In Tahiti, some women organize small groups whose members take turns receiving a tiffaifai. Only one woman may actually create it, but the members contribute a small sum of money on a regular basis to purchase the materials. The creator herself takes her turn in receiving a finished one.

Although a woman may join a group primarily for practical reasons, most women consciously choose to create tîfaifai within a group context in order to reflect their membership to and support of a particular group and its goals. Women who create tiffaifai by working in groups often do so on the basis of work, neighborhood, and church affiliations; their kinship and friendship bonds; and their alliance with others who have similar interests. In many cases, organizing principles overlap, as, for example, women who are friends as well as members of the same congregation.

By joining others in the common goal of creating tîfaifai for a specified purpose, a woman can express personal convictions and strengthen interpersonal bonds. She indicates to people within and outside the group that she has certain things in common with the other members. She may also gain respect, prestige, and status within the membership since women with special talents for designing, sewing, and organizing often receive praise from others within a group.

At any given time, a woman may belong to more than one type of group which periodically creates tiffaifai or is organized solely for that purpose. During her lifetime, a woman may belong to many groups with different organizational principles and purposes. Her affiliation with one or more groups, and her position within a group as chief decision-maker, primary organizer, or fellow seamstress often reflects her roles in societal contexts outside the group and serves to strengthen them.

A second way in which women may use tîfaifai as a vehicle for self-expression is in the decision making process involved in artistic choices. A woman makes artistic decisions when she elects to use particular designs, construction techniques, sewing methods, fabric, and colors. 
Artistic choices provide women with wide variation in personal expression. Convictions, loyalties, preferences, and ideas can all be expressed aesthetically. Although one message may predominate in any given tîfaifai, most $t \bar{i}$ faifai are layered with multiple meanings as complex as the personalities of their makers.

Throughout eastern Polynesia, a woman's choice to make an appliqué or piecework tîfaifai is based on accepted regional aesthetics. In addition, specific designs, construction techniques, fabric colors, and artistic embellishments may all communicate a woman's identification with a regional aesthetic. In the contemporary mileau of inter-island travel, exchange of information, and $t \bar{t}$ faifai exhibitions, a woman's artistic decisions represent a conscious effort to identify herself with a particular cultural heritage and group of islands. In $\mathrm{Ha}-$ waii, for example, women create a design known as "Royal Symbols" which incorporates the historical Hawaiian monarchy's symbols of the crown and the $k a \overline{h i l i}$, a feather standard. The design is almost invariably executed in red and yellow, the royal colors, and the appliqué textile is quilted in the distinctive Hawaiian style of following the contours of the design.

In some cases, when women "borrow" aesthetic features of other islanders, they attach labels to the style or the motifs which signal to others that the $t \bar{i}$ faifai does not reflect their identities in the same way as their own tîfaifai. Alternatively, borrowed elements may be modified for more complete incorporation, as in the case of one Hawaiian artist who obtained a pattern for a Society Islands "Tahitian Flower" motif and transformed it into a Hawaiian quilt with distinctive Hawaiian construction techniques of quilting, renaming the design "Tahitian Beauty."

Women throughout eastern Polynesia express their love for and their identification with their islands by creating tîfaifai which display the islands' flora and fauna. Many women in the Society Islands create at least one tîfaifai with a "Tahitian Flower" design because the flower is a national symbol. Women often create "Tahitian Flower" designs which display the flower motifs arranged as an island hei (a neck or head garland). Another tîfaifai design created only by women of the Society Islands is the " "Apetahi Flower," named after a flower that islanders prize for its fragrance, beauty, and rarity. The " 'Apetahi Flower" design is also cherished by islanders because the flower is a central element in a well-known legend about two lovers.

Political, as well as geographical identification, may figure in a woman's artistic decisions, as seen in the Hawaiian quilt Deborah Kakalia created for the American Bicentennial. Basing her "American Flag" quilt on an older popular Hawaiian quilt design called "My Beloved Flag," the artist referenced her culture's heritage at the same time that she expressed her patriotism during the American Bicentennial. The traditional Hawaiian design, "My Beloved Flag," popular since 1898 when the Hawaiian Monarchy was overthrown, features the monarchy's flag and coat of arms. In her bicentennial quilt, Kakalia substituted the American flag for the monarchy's flag. By creatively retaining the artistic arrangement of flag motifs from the historical design and adding $\mathrm{Ha}-$ 
waiian symbols in the center of the quilt, Kakalia made a very personal statement about her identity and pride as a member of Hawaiian culture and a United States citizen.

At the same time that women express their identification with others as members of a geographical/political area by comforming to regional aesthetic standards, there is a great emphasis placed on individual identity. In general, Polynesians place great emphasis on individual creativity in decisions about tîfaifai designs. Although careful stitching and construction are essential for any well-made tiffaifai, most Polynesians agree that creating a design is the most difficult aspect and the one that requires the greatest skill. For that reason, Polynesians regard women who are highly competent in all aspects of creating tîfaifai as experts. Temana Vahine of Rurutu in the Austral Islands, for example, is recognized as a rangatira or "chief " of tîfaifai makers in her village. Her fame extends beyond her own village to other inhabitants of the island and even to Tahiti, where her tîfaifai have been displayed in contests. Temana Vahine creates many tîfaifai by herself, executing all the work; however, she also participates in a group of women who share their services with one another in making handicrafts. When Temana Vahine works with the group, she designs the tiffaifai which women in the group request. She has a repertoire of several patterns, many of which she modifies from motifs in Western sewing books. Women select a pattern and purchase fabric in colors they prefer, but it is Temana Vahine who decides how the colors will be utilized within the design, and it is she who directs the work of others in sewing the piecework tîfaifai together in correct order. Temana Vahine's prowess as an expert creator of tîfaifai rests on her organizational abilities as well as her talent for calculating the effects of color and design. All tiffaifai created within the group as a result of group activity are still considered to be the creative work of Temana Vahine.

Women place greatest emphasis on individual creativity in their decisions about designs. Since a tîfaifai is often viewed as an extension of its creator, Polynesians adhere to an ethical code which safeguards the originality of a woman's design. Polynesians recognize the creator as the rightful owner of her design to share or keep as she pleases.

A woman may take special measures to guarantee her "rights" over the design. One woman in Rarotonga said that a woman must register a tiffaifai design with the local governmental officials to "patent" it. Although local authorities say that such a procedure doesn't exist, the woman's statement indicates her strong feelings about the importance of originality.

Some women create only one or a few tiffaifai with a particular design and then destroy the pattern in order to preserve the originality of the design. As one Tahitian woman recalled, "My mother made three tiffaifai with a basket of fruit. She gave one to me, one to my cousin, and one to her friend. Then she tore up the pattern." By so doing, the woman ensured the uniqueness of her gifts. 
Women often refer to the design of a particular tiffaifai in their keeping as that belonging to a grandmother, aunt, friend, or mother. The tiffaifai's design, and by extension the tiffaifai itself, becomes a symbol of a particular person, extending the person's identity through time. The memory-identity often becomes the most important meaning attached to a tiffaifai as it ages. "My mother died last year. We buried one of her tîfaifai with her, but I kept this one. I don't use it. I just keep it as a souvenir of her."

Although Polynesians emphasize originality in the design of a tîfaifai, a woman can claim originality by modifying a popular pattern commonly known to all. Throughout eastern Polynesia, there are a number of popular designs which provide women with the inspiration for creating an endless variety of individual interpretations. For example, the "Tahitian Flower" of the Society Islands and the "Breadfruit" of the Hawaiian Islands are common designs which have hundreds of variations as a result of different personal interpretations. Each design is unique to its creator and therefore recognized as her own.

The significance of the tiffaifai design as a symbol of personal identity is further illustrated in a relatively recent phenomenon among some Hawaiian women who sell their designs for commercial profit. Such women may "sign" their quilts by incorporating a distinctive artistic feature, such as a star, into all their designs. Thus, when another duplicates the design, she also replicates the original artist's artistic signature. Original work by the artist herself may, in addition, bear her embroidered signature.

The creation of highly original designs appears to be especially prevalent in the Hawaiian Islands. This may be attributed to a long standing tradition in Hawaiian quilts for abstract and nonrepresentational designs which bear names such as "Press Gently" and "The Wind that Wafts Love From One to Another." In addition, the ethical code of preserving originality has always been particularly important to the Hawaiians. Historically, women sometimes composed derisive songs to embarrass others who copied their designs, and they did not display their quilts until they were completed in order to prevent anyone from imitating their designs. As a result of this emphasis on originality, many women closely guarded their patterns and shared them only with close friends or family members (Jones 1973:12-13). Even today, many Hawaiian women are reluctant to have their quilts photographed.

Perhaps the most important aspect of the emphasis on individuality in tiffaifai designs is that it allows a woman to communicate many personal feelings and ideas. As Christians, some Polynesian women elect to use biblical themes in their tîfaifai. In a turn-of-the-century Hawaiian quilt, entitled "The Beautiful Unequaled Gardens of Eden and of Elenale," the creator juxtaposed the biblical theme of the Garden of Eden with a popular Hawaiian romantic story of the late 19th century. The creator of the quilt designed the main characters of the story, Elenale and Leinaala, to appear as Hawaiian royalty. The combination of a biblical theme, a romantic story, and a reference to Hawaiian royalty within the same context represents one woman's unique interpretation of 
all three elements. The equation of the royal Hawaiian couple with Adam and Eve, as well as with the lovers of the popular romance, implied in the quilt's design, served as the creator's expression of the integration of foreign and indigenous factors.

Another unique tîfaifai design which expresses its creator's devotion to the Christian faith is Temana Vahine's contemporary representation of Christ. Based on a drawing from a Western needlework book, Temana Vahine's design is executed in bright, contrasting colors and includes decorative border designs and the Tahitian inscription Iesu Mesia (Jesus Mesiah).

Much of a woman's definition of self is tied to the roles she plays in interpersonal relationships, and women often express their bonds with others through their artistic decisions about tîfaifai. Some women give personal expression to representational or abstract designs by using the design as a private symbol whose full meaning may be known to only a few people or to the woman alone. One Hawaiian grandmother, for example, who made a different Hawaiian quilt for each of her grandchildren, created one with a breadfruit design for a granddaughter who, as a small child, had enjoyed eating an unusually large amount of breadfruit. Another Hawaiian quilter, Elizabeth A. Akana, designed a quilt called Käleo Aloha, "The Voice of Love," about which she said:

This piece tells of the love legend of the naupaka flower. After tearing the flower in her hair in half, the princess gave half to her lover who[m] she was forbidden to see again. She kept the other half. At this time she proclaimed that "Love will live forever through the flower." It is my wish that love will be forever in my daughter's life.

Personal symbolism was also used by a Society Islands woman who directed several kinswomen in creating four tîfaifai as wedding presents for her son and daughter-in-law. She created a pandanus fruit design, Hei Fara, for one of the tîfaifai. As she explained, "The pandanus fruit is made into crowns [decorative head wreaths] which we wear when we are happy [on festive occasions, such as weddings]. My son is like a crown for me."

Descriptive names associated with a particular design may also carry hidden meaning, not understood by most people. Kakalia, the renowned Hawaiian quilter mentioned previously, made a taro plant design which she named Laniakea o Kono. Originally, Kakalia did not select the design for symbolic reasons, but after learning that taro once grew abundantly on the island of Hawaii where she and others were gathered for a Hawaiian quilt exhibition, she named it for the historical spot. Considering its name and design, Kakalia decided to present the quilt to another famous quilter from the island of Hawaii. Thus, through her quilt, Laniākea o Kono, Kakalia commemorated a historical location, a Hawaiian quilt exhibition, and a warm friendship, all at the same time.

Much of a Polynesian woman's definition of herself is tied to the roles she plays in interpersonal relationships. As seen from previously cited examples, 
women can express their bonds with others through their artistic decisions about tîfaifai. In addition to creating designs that express a woman's personal feelings about another, shared memories, or another's preference for certain designs, Polynesian women sometimes incorporate the name of the person for whom the tîfaifai is created and/or a sentiment, date, and signature. By adding such information in the form of appliqué, piecework, or embroidered words, the makers of $t \bar{f} f a i f a i$ give personal expression to their interpersonal ties with others. A woman's role as mother, grandmother, or friend, for example, is expressed when she integrates the name of a son or daughter, grandson or granddaughter, or a friend into a tîfaifai.

On the island of Rurutu, mothers often include a son or daughter's name into a tîfaifai designated to become a wedding present for that child. The women "write in" their children's baptismal and family surnames by creating the names in block letters with the small squares of cloth which they use to piece an entire tîfaifai design together. Even though parents present the tîfaifai at their children's marriages, occasions upon which both men and women receive new marriage names, and it is ostensibly for both husband and wife, the name on the tîfaifai expresses the strong familial bonds which continue between an individual and his or her family. When a woman incorporates her daughter's name in a tiffaifai, she makes the continuing bond between a daughter and her parents explicit. Even though a woman is associated with her husband's surname and family and is usually addressed by her marriage name, her maiden name on the tifaifai serves to remind others of her continuing bonds with her natal family.

The third way in which women can communicate information about themselves through tîfaifai centers around their decisions regarding tîfaifai uses. Simply by owning tîfaifai, a woman uses the objects for self-expression.

Tiffaifai are associated with women's roles in domestic contexts. The materials, tools, and skills that a woman uses to make tîfaifai reflect the traditional feminine role of creating clothing and household articles. In addition, women usually display tiffaifai in their homes.

In Hawaiian Quilts, Jones points to tîfaifai as a symbol of a woman's femininity in the domestic context. According to a story collected by the author, a young Hawaiian woman fell in love with a Chinese. Her parents opposed the marriage, but when at last her mother did consent, the mother made it clear that the daughter could have none of the calabashes or other Hawaiian things, including the quilts intended for her.

The couple moved to Honolulu. The young wife was ashamed before the other women because she had no quilt for her bed. She purchased the necessary material but had no pattern, and she was too humiliated to ask for one. Then one night as she lay asleep she dreamed a pattern. The dream was so vivid that it awakened her and, rising, she cut the design direct from the material and basted it upon the background before going back to sleep. In the morning she was delighted with her handiwork. A friend who helped her finish the quilt named it Ka La'i o Pua (The Calm of Pua Lane). [Jones 1973:5] 
Owning tîfaifai as a woman is still important, as echoed in a contemporary Cook Islands woman's declaration, "If I did not have any tîfaifai, I would not be a woman!"

Tífaifai are part of a woman's personal wealth. Many women strive to acquire a large number of them by making their own or by purchasing some made by others. Tifaifai that are given to a man become the property of his wife in the sense that she cares for them and uses them as part of her household furnishings. A woman who knows how to design and construct tîfaifai can create her own wealth in tiffaifai after the necessary expenditures in purchasing materials. A woman who doesn't know how to make tîfaifai must either buy them, commission someone for money to create them for her, or rely on the goodwill of friends and relatives to provide them.

Because tîfaifai are so valuable, many women keep them under lock and key. Other women, however, display them on beds on a fairly regular basis as an indication of their wealth in tifaifai and in imitation of the Western practice of decorating the home with expensive furnishings. When a woman places a $t \bar{i}-$ faifai on the beds in her house, she is displaying one of her most valuable sources of wealth.

In some instances, an impressive collection of tîfaifai is a direct reflection of a specific aspect of a woman's identity. Minister's wives, for example, often own unusually large numbers of tiffaifai as a result of their roles. Such women may accumulate tîfaifai as presents, through obligations to purchase tîfaifai at church bazaars, or as a result of the necessity to furnish their homes in an appropriate manner for special occasions.

One of the most important ways in which women use tiffaifai is by decorating their homes with them on such special occasions as church holidays and family celebrations. A woman who has a sizeable collection of tiffaifai to display in her home, either through her own efforts or those of others, gains prestige as a consequence.

Women communicate a complex set of messages when they display tîfaifai on beds, walls, and, in some cases, even the floors of their houses, during special occasions such as church holidays, government health inspection tours, and family celebrations. Depending on the specific context, a woman may express her sense of identification with her religion, her duty as a responsible citizen, or her fulfillment as wife/mother. Likewise, when a woman uses $t \bar{i}$ faifai to decorate guests' beds, she communicates her role as hostess. Almost without exception, a woman's use of tîfaifai as decoration in the home communicates more than one facet of her identity.

In addition to displaying tîfaifai in the home, women often bestow them upon others. When women give tîfaifai to relatives, friends, and more rarely to political and religious leaders, they present objects of socially acknowledged value which communicate a wide range of information about women's identities, feelings, and thoughts. The occasions upon which women present tîfaifai and the meanings behind such presentations vary with the relationships.

Generally, women give tîfaifai to others as gifts on an individual basis. A woman who gives a tîfaifai to a specific individual expresses a bond which ex- 
ists between the two. The most significant interpersonal relationships which women emphasize are those with their descendants. Through a gift of tiffaifai, a woman can convey her strongest emotions: love, respect, pride, happiness, and sorrow. Many women make tîfaifai to present to each of their children and grandchildren. Women may give them to their descendants at any time; however, women present most tiffaifai on special occasions such as birthdays and farewells. Weddings are without doubt the most important occasion for presenting such a gift.

Beyond expressing her emotions in material form through a gift of tîfaifai, a woman may also use a tîfaifai as a substitute for her presence, thus creating a powerful statement using a tiffaifai as a symbol of her identity. Women often make tîfaifai intended as wedding presents long before their children are to be married. As a woman on the island of Rurutu said, "I am making tiffaifai for my children now. It is important to do this in case I die before they marry. Even if I do not see them marry, they will still have the tiffaifai." At the same time that the tiffaifai would convey the deceased's feelings for her child, it would serve to remind people of the identity of the maker.

An excellent illustration of the function of tiffaifai as a substitute and a reminder of the creator may be cited in an incident in which a woman of Rurutu sent several tîfaifai, originally created for her son's marriage, to Tahiti to be buried with him. Because she could not afford to make the trip herself, she sent the tîfaifai as a substitute for her presence at the funeral.

Although the largest number of gift presentations are done on an individual basis, many tîfaifai are given by groups of women. In these cases, the women usually represent larger groups of people, such as an entire congregation or community. During a farewell ceremony for a minister's widow on the island of Rarotonga in the Cook Islands held in 1978, a group of women presented a tiffaifai which they had made as a group. The bond expressed by the gift extended beyond the specific group of women and symbolized the link which all the members of the congregation felt with the widow. The women who created and presented the tiffaifai acted as representatives of the whole congregation and in so doing expressed their identities as members of the larger group.

At times, an individual may express very personal feelings within the context of a group presentation. For instance, in a special farewell ceremony for a minister and his family on the island of Rarotonga, also held in 1978, female congregational members created four tîfaifai to present in a special ritual manner to the departing family. The family sat in a place of honor and the four unfolded tiffaifai were carried one at a time by several women and placed across the laps of the family members. The last one, which was the special present of the wife of the assistant minister, was carried forward in the same manner, but the donor had instructed the women to place it over the heads of the family members for a few minutes before lowering it to their laps. The contrast of the last tiffaifai presentation with those of the other three drew attention to the unique quality of the act and served as a statement of the very personal emotions felt by the donor. 
When women present tîfaifai to important Western governmental officials or, in the case of Cook Islanders, to members of the English royalty, they use the tiffaifai to communicate expressions of their own and fellow islanders' ethnic identity. Likewise, women represent others as well as themselves when they display tiffaifai in the context of national events or holidays to assert their cultural pride and identification within a political context which emphasizes the achievements of another culture or a larger political entity. In the Society Islands, tîfaifai figure in some of the festivities associated with the Polynesian version of French Independence Day. Women may use tîfaifai to decorate parade floats, fair booths, and festival buildings.

Yet another way in which women may use tîfaifai as vehicles for formulating and expressing their identities is by selling tîfaifai. Women often create tîfaifai to sell to benefit organizations such as churches and women's clubs. A woman's participation in a collective profit-making enterprise is directly related to her motivations for participating within a particular organization. Tífaifai which women make individually or collectively are usually sold at bazaars sponsored by the organization or serve as prizes for raffles. Women donate their time, and sometimes the fabric, to create tiffaifai for the organizations they support.

Many women make tîfaifai privately to sell to a local clientele or to tourists. A woman who knows how to make tîfaifai can gain some financial independence and create a role as an income producer for her family. In the Society Islands, especially in the capital of Pape'ete, women have been making tîfaifai for commercial profit for at least 50 years, but until recently all of them were sold to other islanders, a practice that still persists in the Cook Islands and the Austral Islands.

With recent innovation of commercial outlets to reach the tourist market, some redefinition of aesthetic standards is occurring. Individual work patterns and a greater reliance on efficiency in techniques and designs are changing the quality and appearance of many tîfaifai. In addition, an emphasis on individual profits has led to greater recognition of individual artistry in tîfaifai exhibitions and contests. In many cases, the trend toward individualization in selling $t \bar{t}$ faifai is fostering a greater identification of individual achievement.

\section{Conclusion}

Unlike women in some societies, whose identities as creators of valuable goods declined or disappeared with the radical changes effected by their contact with Westerners, women of eastern Polynesia continued to sustain a much valued role by creating tiffaifai. By selecting aspects of Western quilting traditions which appealed to their sense of aesthetics and combining those with the familiar activities and artistry associated with bark cloth, Polynesian women shaped a vehicle of communication which allowed them to retain important aspects of their identities from traditional culture. At the same time, the creation of the reintegrated art form of tiffaifai allowed women to continue to 
shape and express their identities from the time of early Western contact to the present. Today, Polynesian women are still actively involved in constructing and communicating information about themselves through tîfaifai and associated activities. As this paper has demonstrated, Polynesian women exercise many options for self expression through tîfaifai. A woman may choose to participate in decision making which is limited to only one or two communication areas, or she may express herself through all three areas of artistic choices, work patterns, and uses for tîfaifai.

The virtually unlimited possibilities for self expression through tiffaifai are integral to the viability of the art form. At different times in their lives, women may be involved in different aspects of the communication processes. At any given point in time, a woman may choose to communicate different messages, singularly or simultaneously. Many women choose to highlight particular aspects of their identities in different contexts. If a woman participates in at least two of the three communication spheres, and constructs a message which, by virtue of its repetitive nature, foregrounds a particular role or part of her selfdefinition, she is able to convey a strong message about an aspect of her identity pertinent to a given situation. Thus, a woman who creates an original $t \bar{t}-$ faifai design, sews the tîfaifai herself, and enters it into a contest, may direct attention to that part of her identity which relates to her perception of self as artist. On the other hand, she may design a tîfaifai with a particular design which expresses her relationship to her child, sew the tiffaifai in conjunction with the child's sisters, and present it at her child's wedding, thus focusing attention on her identity as a mother. The same woman may also choose to foreground different messages in different communication areas as, for example, were she to emphasize her ethnic identity in artistic choices, church affiliation in work patterns, and kinship bonds in use decisions.

As this study suggests, the different areas of communication associated with an art form are rich sources for examining the means by which people shape and present their identities to others. An examination of the various means by which Polynesian women utilize tîfaifai for self-expression has revealed that the complex nature of communication inherent within the creation and use of tîfaifai is mirrored by the multifaceted expressions of identity revealed by Polynesian women to themselves and others.

\section{Notes}

A version of this paper was presented as one of the Visiting Scholars' Evening Lecture Series at the 1983 International Summer Institute for Semiotic Structural Studies. I wish to express gratitude to Beverly J. Stoeltje and Richard Bauman for their remarks and criticisms of the original draft. The paper is based on fieldwork in eastern Polynesia, conducted between 1977 and 1978. I am deeply grateful to the Polynesian women who generously contributed their time and knowledge to my work; to my dissertation advisor, Claire Farrer, for her valuable insights and comments on papers related to this topic; and to my parents who aided me emotionally and financially in conducting my fieldwork.

${ }^{1}$ Tifaifai (to patch) will be used as a generic term for both piecework and appliqué textiles which are called tîfaifai in the Society Islands, tivaevae in the Cook Islands, iripiti or tîfaifai in the Austral Islands, and kapa or 
Hawaiian quilts in the Hawaiian Islands. The term tifaifai, used both as a singular and plural noun according to context, has been selected because it is a term known and accepted by most eastern Polynesians. However, when referring specifically to Hawaiian piecework and appliqué textiles, I will use the term quilt since the term tifaifai is unfamiliar to the Hawaiians and the Hawaiian textiles are, in fact, true quilts in construction.

${ }^{2}$ The replacement of fine bark cloth with tîfaifai in eastern Polynesia was not paralleled in western Polynesia where bark cloth continues to be created. For a discussion of the regional differences in the use of bark cloth and tîfaifai between eastern and western Polynesia see Hammond 1981.

${ }^{3}$ Kaeppler has noted: "Whereas barkcloth kapa has an overall watermark design which permeates the whole sheet and a second design printed on the upper surface, a kapa quilt has a quilted design which is sewn through the entire quilt and another design appliqued [or executed in piecework] on the upper surface" (1979:189).

${ }^{4}$ Early literary references and photographs of tifaifai in the Society Islands, for example, are of piecework (sometimes called patchwork). On 8 January 1858, a Frenchman, M. G. Cuzent, attended a Tahitian marriage and recorded seeing piecework tifaifai used as decoration for the inside of the feast house (fare tämáara'a) (1860:58-59). In 1877, Constance F. Cumming, who traveled to Tahiti with the Catholic bishop of Samoa, also recorded the use of tifaifai as ornamentation inside a Tahitian feast house. Cumming's reference to the tifaifai as quilts in the following passage is probably inaccurate and a reflection of her recognition of the close visual similarities between Tahitian tiffaifai and Western quilts.

Ere long we were summoned to breakfast-a native feast in a native house, which was decorated in most original style, with large patchwork quilts. These are the joy and pride of the Tahitian women, and so artistic in design as to be really ornamental. [1877 II:3-4]

Cumming also wrote about the tîfaifai which were placed on guests' beds.

and such pretty coverlets of patchwork, really triumphs of needle-work. Those most in favor have crimson patterns on a white ground, but the designs are highly artistic. [1877 I:298-299]

${ }^{5}$ There are American appliqué quilts which date to the period between 1836 and 1858, Jones's (1973) proposed dates for the origin of the Hawaiian quilt, which shares striking similarities with Hawaiian appliqué quilts in the use of quadriaxial symmetrical designs and overall design arrangements with one central pattern or a central pattern with smaller surrounding designs and a decorative border. Moreover, while the Hawaiian method of cutting an overall appliqué design from a single piece of fabric is unique to Polynesia, the Hawaiians may have developed the technique after seeing small Western applique designs created in a similar manner. Similarities in patterns and design arrangements between some early American and Polynesian quilts suggest a strong Western influence on the Hawaiian appliqué tradition, resulting from missionary activity and Western settlement in the Hawaiian Islands.

${ }^{6}$ For full descriptions of Hawaiian, Society, Cook, and Austral Islands tîfaifai, consult Jones (1973), O'Reilly (1959), and Hammond (1981).

\section{References Cited}

Altonn, Helen. 8 September 1975. Beautiful Patterns Stitched with Love. Honolulu Star-Bulletin. Boserup, Ester. 1970. Women's Role in Economic Development. New York: St. Martin's Press.

Brotten, Bronwyn V., and Ann Lang. 1973. Zulu Beadwork African Arts 6:8-13.

Cooper, Patricia, and Norma Bradley Buferd. 1977. The Quilters, Women and Domestic Art. Garden City, NY: Doubleday.

Cumming, C. F. 1877. A Lady's Cruise in a French Man-of-War. Vols. I and II. London: Blackwood and Sons.

Cuzent, M. G. 1860. Iles de la Sociétè. Rochefort: Imprimerie Chez Thèze.

D’Azevedo, Warren L. 1966. The Artist Archetype in Gola Culture. Desert Research Institute Preprint No. 14. University of Nevada, Reno (revised and reissued, 1970). 
Dewhurst, C. Kurt, Betty MacDowell, and Marsha MacDowell. 1979. Artists in Aprons: Folk Art by American Women. New York: E. P. Dutton in association with the Museum of American Folk Art.

Eber, Dorothy, ed. 1972. Pitseolak: Pictures Out of My Life. Montreal: Design Collaborative Books.

Ellis, William. 1969[1831]. Polynesian Researches. Rutland, Vermont: Charles E. Tuttle Co.

Forge, J. Anthony. 1967. The Abelam Artist. In Social Organization: Essays Presented to Raymond Firth, ed. Maurice Freedman, pp. 65-84. London: Cass.

Gerbrands, Adrian. 1967. Wow-Ipits: Eight Asmat Woodcarvers in New Guinea. Translated by Inez Seeger. The Hague: Mouton.

Graburn, H. H., ed. 1976. Ethnic and Tourist Arts, Cultural Expressions from the Fourth World. Berkeley: University of California Press.

Hammond, Joyce D. 1981. Tífaifai of Eastern Polynesia: Meaning and Communication in a Women's Reintegrated Art Form. Ph.D. dissertation, Anthropology Department, University of Illinois.

Jones, Stella M. 1973. Hawaiian Quilts, 2nd ed. Honolulu: Daughters of Hawaii, Honolulu Academy of Arts, and Mission Houses Museum.

Kaeppler, Adrienne L. 1979. A Survey of Polynesian Art. In Exploring the Visual Art of Oceania, ed. Sidney M. Mead, pp. 180-191. Honolulu: The University Press of Hawaii.

Munn, Nancy. 1973. Walbiri Iconography: Graphic Representation and Cultural Symbolism in a Central Australian Society. Ithaca, NY: Cornell University Press.

O'Reilly, Patrick. 1959. Note sur les “Ti Fai Fai” Tahitians. Journal de la Sociétè des Océanistes 15:165-177.

Plews, Edith Rice. 1973. Hawaiian Quilting on Kauai, an Address Given to the Mokihana Club at Lihue, Kauai, March 1, 1933. Kauai Museum Publications, Lihue.

Sanday, Peggy R. 1974. Female Status in the Public Domain. In Woman, Culture and Society, eds. Michelle Zimbalist Rosaldo and Louise Lamphere, pp. 189-206.

Salvador, Mari Lynn. 1978. Yer Dailege! Kuna Women's Art. Albuquerque, NM: The Maxwell Museum of Anthropology.

Smith, Marian W., ed. 1961. The Artist in Tribal Society. Proceedings of a Symposium held at the Royal Anthropological Institute. London: Routledge and Kegan Paul.

Smith, Thomas. 1825. The History and Origin of the Missionary Societies. Vol. II. London: Thomas Kelly and Richard Evans.

Teilhet, Jehanne H. 1978. The Equivocal Role of Women Artists in Non-Literate Societies. Heresies 1:96-102.

Thurston, Lucy G. 1882. Life and Times of Mrs. Lucy G. Thurston. Ann Arbor, MI: S. C. Andrews.

Wahlman, Maude. 1974. Contemporary African Arts. Chicago: Field Museum of Natural History. Whitten, Dorothea S., and Norman E. Whitten, Jr. 1976. Ceramics and Symbolism of Ecuador's Rainforest. Sacha Runa Research Foundation Occasional Publications No. 4. Urbana, Illinois. Willet, Frank. 1978. An African Sculptor at Work African Arts II:28-33. 